\title{
Dendrimers as Color-Stabilizers of Pyranoanthocyanins: The Dye Concentration Governs the Host-Guest Interaction Mechanisms
}

\author{
Luís Cruz,* Juan Correa, Nuno Mateus, Victor de Freitas, Maun H. Tawara, \\ and Eduardo Fernandez-Megia*
}

Cite This: ACS Appl. Polym. Mater. 2021, 3, 1457-1464

Read Online

Џlll Metrics \& More

Article Recommendations

Supporting Information

ABSTRACT: Anionic dendrimers have recently emerged as hosts $(\mathrm{H})$ for the color stabilization of the flavylium cation of anthocyanin guests (G). The interaction with a promising, more hydrophobic pyranoanthocyanin illustrates how the structure and concentration of the dye modulate the host-guest interaction mechanisms. NMR and UV-vis titrations (host over guest, from G/H ratio 2089 to 45 ) showed that at relatively low dendrimer-to-dye concentrations, ion pairs at the dendrimer periphery prevail over dye encapsulation. This promotes the deaggregation of the dye, not previously observed with anthocyanins, and related to the more hydrophobic nature of this dye (deshielding of the dye ${ }^{1} \mathrm{H}$ signals, higher $T_{2}$ relaxation times, constant diffusion coefficient). As the dendrimer concentration increases, the dye encapsulation, earlier unseen with structurally simpler flavylium

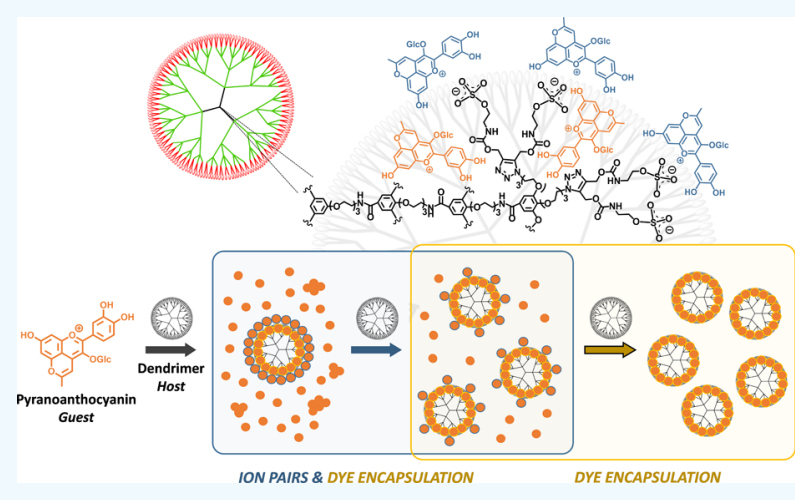
dyes, becomes dominant (shielding and broadening of the dye ${ }^{1} \mathrm{H}$ signals and lower $T_{2}$ and diffusion coefficient). The interaction parameters of the encapsulation process $\left(K \sim 4.51 \times 10^{4} \mathrm{M}^{-1}, n \sim 150\right)$ indicate the binding of ca. one pyranoanthocyanin molecule by each sulfate terminal group. Our results provide insights into the ability of dendrimers to host structurally diverse pyranoflavylium-based dyes and how the structure of the latter modulates the range of interactions involved. The encapsulation ability of this dendrimer to such $\mathrm{pH}$-sensitive dyes is envisioned for the host-guest sensing applications such as $\mathrm{pH}$-responsive systems used for example in food smart packaging.

KEYWORDS: NMR, UV-vis, pyranoanthocyanins, dendrimers, encapsulation, $p H$ sensors, host-guest interaction

\section{INTRODUCTION}

Flavylium-based dyes represent a huge family of natural and synthetic pigments, which include anthocyanins, 3-deoxyanthocyanins, and anthocyanin-derived pigments (e.g., pyranoanthocyanins) with interesting applications as colorants for textiles, foods, cosmetics, and smart and functional materials because of their $\mathrm{pH}$ and light responsiveness. ${ }^{1}$ Among them, pyranoanthocyanins (Figure 1) display characteristic chromatic features and a more intense orange color because of a hypsochromic shift of their $\lambda_{\max }(478-510 \mathrm{~nm})$ compared to anthocyanins $(516-541 \mathrm{~nm}) .^{2}$ Their pyranic ring substitution impedes the production of hemiketal colorless species and leads to more evident color changes than anthocyanins in response to $\mathrm{pH}$ variations, an advantage of sensing applications. ${ }^{3,4}$ Furthermore, bearing their natural occurrence and high biocompatibility, these pigments find great potential as $\mathrm{pH}$ sensors for real-time monitoring of food spoilage. Thus, as $\mathrm{pH}$ increases, the flavylium cation $\left(\mathrm{AH}^{+}\right)$undergoes very fast proton transfer reactions, leading to the formation of neutral and anionic quinoidal bases $\left(\mathrm{A}\right.$ and $\left.\mathrm{A}^{-}\right)$with different colors. $^{4,5}$
Supramolecular host-guest systems have found application from materials to the biomedical arena with the ultimate goal of improving the physicochemical properties of the guests. ${ }^{6,7}$ In nature, anthocyanins participate in complex supramolecular structures via different mechanisms (self-association, copigmentation, metal complexation), rendering some of the beautiful colors found in flowers. ${ }^{8}$ Because of their globular architecture at the nanoscale, high functional surface, and inherent multivalency, dendrimers are considered archetypal macromolecular hosts. ${ }^{9-11}$ The first dendrimer-based anthocyanin host has recently been described: a water-soluble, polyanionic gallic acid triethylene glycol (GATG) ${ }^{12,13}$ dendrimer (functionalized with 162 terminal sulfate groups) that shows a great impact on the color-stabilizing mechanisms of the red flavylium cation of anthocyanins via reversible

Received: November 27, 2020

Accepted: February 20, 2021

Published: March 3, 2021 

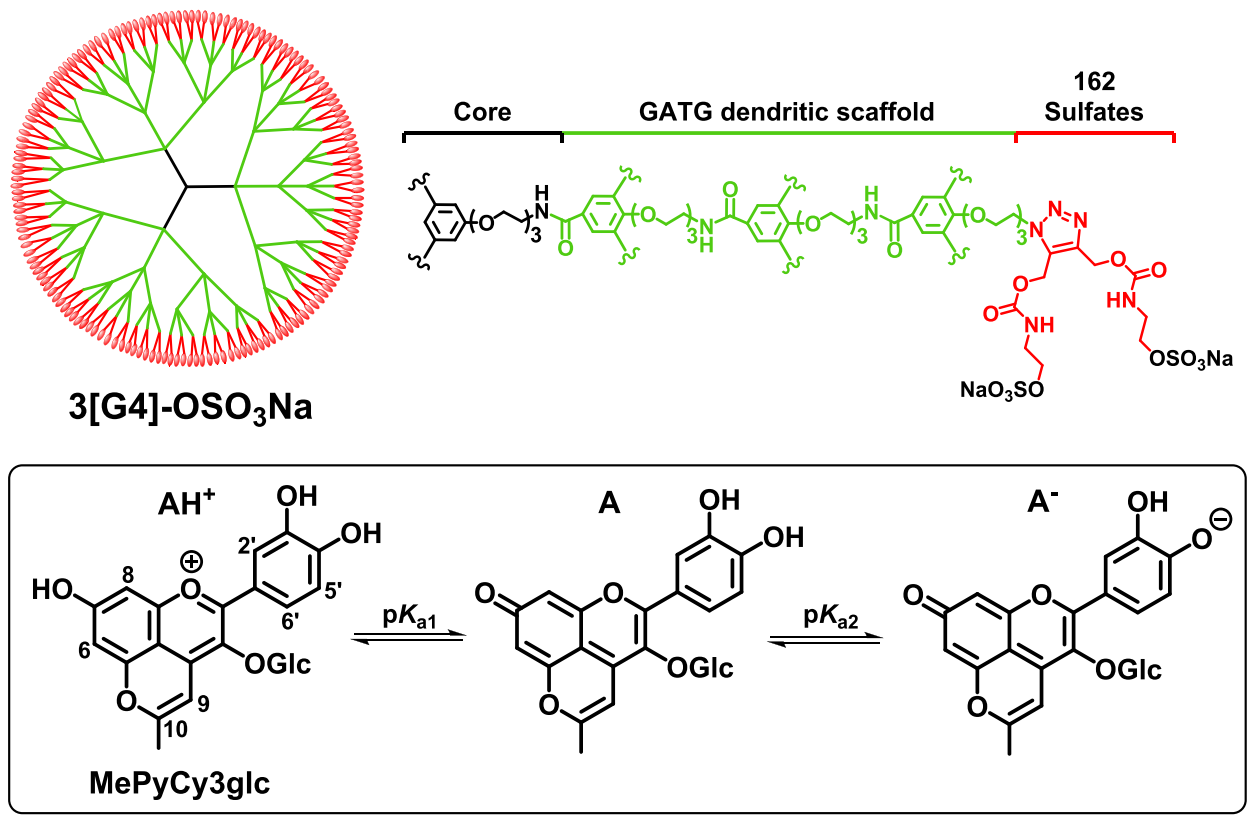

Figure 1. Structures of $3[\mathrm{G} 4]-\mathrm{OSO}_{3} \mathrm{Na}$ dendrimer carrying 162 sulfate groups (host or $\mathrm{H}$ ) and 10-methylpyranocyanidin-3-glucoside cation (MePyCy3glc, guest or $\mathrm{G}$ ) and its chemical equilibrium species as a function of $\mathrm{pH}$.

contact ion pairs at the dendrimer periphery. ${ }^{14}$ In this work, a deep mechanistic study of the interaction of GATG-based dendrimers with a more hydrophobic pyranoanthocyanin-type pigment (MePyCy3glc) with promising $\mathrm{pH}$-sensing applications was performed using NMR $\left({ }^{1} \mathrm{H}\right.$ titration, ${ }^{1} \mathrm{H} T_{2}$ relaxation, DOSY, NOESY) and UV-vis spectroscopy (Figure $1)$.

\section{MATERIALS AND METHODS}

Reagents. Theorell and Stenhagen universal buffer ${ }^{15}$ was prepared as described in the previous work. ${ }^{14}$ Cyanidin-3-glucoside chloride salt was obtained by extraction from blackberries (Rubus fruticosus L.). The purification process was performed as described elsewhere, ${ }^{16}$ and the purity of the pigment was assessed by HPLC-DAD and ${ }^{1} \mathrm{H}$ NMR spectroscopy. The dendrimers were obtained by synthesis as described below. Other reagents were obtained from Sigma-Aldrich (Madrid, Spain).

Synthesis of Dendrimers. $3[\mathrm{G} 4]-\mathrm{OSO}_{3} \mathrm{Na}$ with 162 terminal sodium sulfate groups (MW: $61672 \mathrm{~g} \mathrm{~mol}^{-1}$ ) was obtained from $3[\mathrm{G} 3]-\mathrm{N}_{3}$ and ammonium 4,11-dioxo-5,10-dioxa-3,12-diazatetradec7-yne-1,14-diyl bis(sulfate) via azide-alkyne cycloaddition (91\%): ${ }^{14}$ ${ }^{1} \mathrm{H}$ NMR $\left(500 \mathrm{MHz}, \mathrm{D}_{2} \mathrm{O}\right) \delta: 7.26-7.12(\mathrm{~m}, 78 \mathrm{H}), 6.26(\mathrm{br} \mathrm{s}, 3 \mathrm{H})$, $5.43-5.16(\mathrm{~m}, 324 \mathrm{H}), 4.71-4.58(\mathrm{~m}, 162 \mathrm{H}), 4.29-4.01(\mathrm{~m}, 564 \mathrm{H})$, $4.00-3.51(\mathrm{~m}, 1038 \mathrm{H}), 3.48-3.32(\mathrm{~m}, 324 \mathrm{H})$ (Figure S8). ${ }^{13} \mathrm{C}$ NMR $\left(125 \mathrm{MHz}, \mathrm{D}_{2} \mathrm{O}\right) \delta: 168.8,157.5,157.0,151.8,141.9,139.6,132.6$, 129.3, 106.1, 72.1, 69.9, 69.5, 69.0, 68.8, 68.3, 67.2, 67.1, 57.1, 53.9, 48.6, 40.0 (Figure S9). IR (KBr): 3446, 2935, 1718, 1542, $1255 \mathrm{~cm}^{-1}$.

Using similar reaction conditions as above from $3[\mathrm{G} 3]-\mathrm{N}_{3}$ and 10,17-dioxo-3,6,11,16,21,24-hexaoxa-9,18-diazahexacos-13-yne-1,26diaminium chloride or but-2-yne-1,4-diyl bis((2-(2-(2hydroxyethoxy)ethoxy)ethyl)(arbamate), cationic $3[\mathrm{G} 4]-\mathrm{NH}_{2} \cdot \mathrm{HCl}$ (162 ammonium groups) and neutral 3[G4]-OH (162 hydroxyl groups) dendrimers were prepared in $92 \%$ yield as control hosts for the interaction with MePyCy3glc.

$3[\mathrm{G} 4]-\mathrm{NH}_{2} \cdot \mathrm{HCl}:{ }^{1} \mathrm{H}$ NMR $\left(500 \mathrm{MHz}, \mathrm{D}_{2} \mathrm{O}\right) \delta: 7.16(\mathrm{br} \mathrm{s}, 78 \mathrm{H})$, 5.40-5.12 (m, 324H), 4.71-4.55 (m, 162H), 4.29-4.02 (m, 240H), $4.00-3.46(\mathrm{~m}, 2334 \mathrm{H}), 3.34-3.17(\mathrm{~m}, 648 \mathrm{H})$ (Figure $\mathrm{s} 10) .{ }^{13} \mathrm{C}$ NMR $\left(125 \mathrm{MHz}, \mathrm{D}_{2} \mathrm{O}\right) \delta: 168.7,157.6,157.0,151.9,141.9,139.7$, 132.7, 129.2, 106.2, 72.0, 69.8, 69.7, 69.4, 69.0, 68.7, 68.3, 66.2, 56.9, 53.7, 48.5, 39.8, 38.9 (Figure S11). IR (KBr): 3383, 2971, 1677, 1201, $1130 \mathrm{~cm}^{-1}$.
3[G4]-OH: ${ }^{1} \mathrm{H}$ NMR $\left(500 \mathrm{MHz}, \mathrm{D}_{2} \mathrm{O}\right) \delta: 7.24-7.10(\mathrm{~m}, 78 \mathrm{H})$, $5.40-5.13(\mathrm{~m}, 324 \mathrm{H}), 4.74-4.58(\mathrm{~m}, 162 \mathrm{H}), 4.26-4.00(\mathrm{~m}, 240 \mathrm{H})$, $4.00-3.40(\mathrm{~m}, 2658 \mathrm{H}), 3.34-3.18(\mathrm{~m}, 324 \mathrm{H})$ (Figure $\mathrm{S} 12) .{ }^{13} \mathrm{C}$ NMR $\left(125 \mathrm{MHz}, \mathrm{D}_{2} \mathrm{O}\right) \delta: 168.4,157.6,157.2,152.1,141.9,139.8$, 132.7, 129.2, 106.1, 72.1, 71.6, 69.8, 69.4, 69.2, 69.0, 68.8, 68.5, 68.3, 60.2, 56.8, 53.6, 48.5, 39.9 (Figure S13). IR (KBr): 3332, 2876, 1708, $1246,1100 \mathrm{~cm}^{-1}$.

Synthesis of 10-Methylpyranocyanidin-3-glucoside Chloride Salt (MePyCy3glc). Cyanidin-3-glucoside chloride salt (50 mg, $0.10 \mathrm{mmol}$ ) was dissolved in a solution of acetone/water 20:80 (v/v). The reaction mixture was stirred at $37^{\circ} \mathrm{C}$ and $\mathrm{pH} 2.9$ for 8 days. The crude product was first prepurified in a Buchner funnel loaded with $\mathrm{RP}-18$ silica gel and the fraction containing the product was eluted with $\mathrm{MeOH} /$ water 20:80 (v/v) solution acidified with $0.1 \mathrm{M} \mathrm{HCl}$. Then, the final purification was performed in a column chromatography loaded with RP-18 silica gel and the product was isolated with $\mathrm{MeOH} /$ water 15:85 (v/v) solution acidified with $0.1 \mathrm{M} \mathrm{HCl}$. After solvent evaporation, the product was freeze-dried and a dark orange powder was obtained with $46 \%$ of yield.

${ }^{1} \mathrm{H}$ NMR (600.13 MHz, DMSO-d $d_{6} /$ TFA 9:1), $\delta$ (ppm): 7.93 (dd, 2.3/8.6 Hz, 1H, H-6'B), 7.80 (d, $\left.2.3 \mathrm{~Hz}, 1 \mathrm{H}, \mathrm{H}-2^{\prime} \mathrm{B}\right), 7.27$ (s, $1 \mathrm{H}$, H9), 7.18 (d, 1.9 Hz, 1H, H-8A), 7.08 (d, $1.9 \mathrm{~Hz}, 1 \mathrm{H}, \mathrm{H}-6 \mathrm{~A}), 6.91$ (d, $\left.8.6 \mathrm{~Hz}, 1 \mathrm{H}, \mathrm{H}-5^{\prime} \mathrm{B}\right), 2.58\left(\mathrm{~s}, 3 \mathrm{H}, \mathrm{CH}_{3}\right)$; Glucose, $4.61(\mathrm{~d}, 7.8 \mathrm{~Hz}, 1 \mathrm{H}$, H-1"), 3.51 (*, 1H, H-6a"), 3.45 (t, $\left.8.1 \mathrm{~Hz}, 1 \mathrm{H}, \mathrm{H}-2^{\prime \prime}\right), 3.28$ (dd, 6.0/ $\left.11.5 \mathrm{~Hz}, 1 \mathrm{H}, \mathrm{H}-6 \mathrm{~b}^{\prime \prime}\right), 3.18\left(\mathrm{t}, 8.8 \mathrm{~Hz}, 1 \mathrm{H}, \mathrm{H}-3^{\prime \prime}\right), 3.13(\mathrm{t}, 9.0 \mathrm{~Hz}, 1 \mathrm{H}$, $\left.\mathrm{H}-4^{\prime \prime}\right), 3.03\left(\mathrm{~m}, 1 \mathrm{H}, \mathrm{H}-5^{\prime \prime}\right) ;{ }^{13} \mathrm{C}$ NMR (125.77 MHz, DMSO-d 6 /TFA 9:1), $\delta$ (ppm): 171.9 (C10), 167.0 (C7), 162.1 (C2), 153.5 (C5), 152.3 (C8a), $152.3\left(\mathrm{C}^{\prime}\right), 145.5$ (C3'), $132.8(\mathrm{C} 3), 124.9\left(\mathrm{C6}^{\prime}\right)$, $120.1\left(\mathrm{C1}^{\prime}\right), 117.1\left(\mathrm{C2}^{\prime}\right), 116.2\left(\mathrm{C5}^{\prime}\right), 107.5$ (C4a), 102.0 (C9), 100.3 (C8), 100.1 (C6), $21.5\left(\mathrm{CH}_{3}\right)$, C4 not assigned; Glucose, 104.3 $\left(\mathrm{C}-1^{\prime \prime}\right), 77.9\left(\mathrm{C}-5^{\prime \prime}\right), 76.5\left(\mathrm{C}-3^{\prime \prime}\right), 74.0\left(\mathrm{C}-2^{\prime \prime}\right), 70.0\left(\mathrm{C}-4^{\prime \prime}\right), 61.5$ (C$\left.6^{\prime \prime}\right)$. LC-DAD/ESI-MS: $[\mathrm{M}]^{+} \mathrm{m} / z$ 487, $\lambda_{\max } 472 \mathrm{~nm} .{ }^{1} \mathrm{H}$ NMR spectrum, 2D COSY, 2D HSQC, and 2D HMBC spectra of $\mathrm{MePyCy} 3$ glc are presented in Figures S4-S7, respectively.

HPLC-DAD/LC-DAD/ESI-MS. The analyses were performed according to the procedures described elsewhere. ${ }^{17}$

Dynamic Light Scattering (DLS). DLS measurements were performed on a Malvern Nano ZS (Malvern Instruments, U.K.), operating at $633 \mathrm{~nm}$ with a $173^{\circ}$ scattering angle at $25^{\circ} \mathrm{C}$. DLS mean diameters were obtained from the volume particle size distribution provided by Malvern Zetasizer Software. DLS size is reported from the intensity particle size distributions. 
NMR Spectroscopy. Unless otherwise noted, NMR experiments were recorded on a Bruker Avance III $600 \mathrm{HD}$ spectrometer operating at $600.13 \mathrm{MHz}$ for ${ }^{1} \mathrm{H}$ and $150.92 \mathrm{MHz}$ for ${ }^{13} \mathrm{C}$, equipped with $5 \mathrm{~mm}$ CryoProbe Prodigy and pulse gradient units, capable of producing magnetic field pulsed gradients in the $z$-direction of $50 \mathrm{G}$ $\mathrm{cm}^{-1}$. The NMR measurements have been done with standard BRUKER pulse sequences, in deuterium oxide $\left(\mathrm{D}_{2} \mathrm{O}\right)$, at $300 \mathrm{~K}$ and at pD 1.4. ${ }^{1} \mathrm{H}$ NMR experiments were performed with water suppression using excitation sculpting with gradients (Hwang and Shaka, 1995), the acquisition time of $1.36 \mathrm{~s}$, relaxation delay of $2 \mathrm{~s}$, and 128 or 256 transients of the spectral width of $10000 \mathrm{~Hz}$ collected into $32 \mathrm{~K}$ time domain points.

NOESY. Typical measuring conditions for the ${ }^{1} \mathrm{H} /{ }^{1} \mathrm{H}$ and $2 \mathrm{D}$ NOESY recorded in the phase-sensitive mode and with water suppression were relaxation delay of $2 \mathrm{~s}, 64-128$ scans, and a total 2 $\mathrm{K}$ data points in $\mathrm{F} 2$ and 256 data points in $\mathrm{F} 1$ over a spectral width of $10000 \mathrm{~Hz}$. NOESY experiments were carried out using a mixing time of $100,200,400,500,700$, and $800 \mathrm{~ms}$ in the phase-sensitive mode.

DOSY. Proton-registered diffusion-ordered NMR $\left({ }^{1} \mathrm{H}\right.$ DOSY) experiments were performed using the bipolar longitudinal Eddy current delay (BPPLED, bipolar pulsed field gradient longitudinal Eddy delay) pulse sequence as described in the literature. ${ }^{18}$ The experimental conditions of DOSY experiments were set according to the previous work. ${ }^{19}$ The diffusion coefficients $(D)$ were obtained by measuring the signal intensity of the methyl protons of the guest.

NMR Relaxation. ${ }^{1} \mathrm{H} \mathrm{T}_{2}$ relaxation experiments were measured at $300 \mathrm{~K}$ in a $11.7 \mathrm{~T}$ Bruker DRX-500 spectrometer $\left({ }^{1} \mathrm{H}\right.$ frequency 500 $\mathrm{MHz}$ ) equipped with a BBI probe with PFG gradients on the $z$-axis using the Carr-Purcell-Meiboom-Gill (CPMG) $)^{20,21}$ pulse sequence with presaturation. After an initial relaxation delay $\left(d_{1}\right)$ of $7 \mathrm{~s}$, the presaturation was applied during $4 \mathrm{~s}$ at the frequency of the residual HOD peak of the solvent $(\sim 4.7 \mathrm{ppm})$ by a continuous wave pulse of low power. A total of 16 durations $(t)$ of the CPMG were explored by a repetition of the single CPMG block with an interpulse delay of 1.4 $\mathrm{ms}$. The durations $(t)$ were explored in independent fids from $1.4 \mathrm{~ms}$ up to a maximum of ca. 5 times the largest ${ }^{1} \mathrm{H} T_{2}$. The fids were acquired as a pseudo-2D spectrum. Each fid acquisition time (aq) was $1.47 \mathrm{~s}$, and the spectral width was $10.6 \mathrm{ppm}$. A total of 24 scans were acquired for each fid. The signal integral $(I)$ at each value of $t$ was fitted to the monoexponential eq 1 to determine the relaxation time $T_{2}$

$$
I(t) / I_{0}=\exp \left(-t / T_{2}\right)
$$

where $I(t)$ and $I_{0}$ are the observed signal integrals at a given value of $t$ and for $t=0$, respectively. OriginPro 8.5 Software (OriginLab Corporation) was used to perform the exponential fittings to obtain the relaxation times $T_{2}$.

${ }^{1} H$ NMR Titration. For the NMR titration, a $261 \mu \mathrm{M}$ solution of MePyCy3glc was prepared in $\mathrm{D}_{2} \mathrm{O}$, with the $\mathrm{pH}$ was adjusted to 1 ( $\mathrm{pD} 1.4$ ), and transferred to $5 \mathrm{~mm}$ NMR tubes. Sodium trimethylsilyl[2,2,3,3-d4]-propionate (TSP, $5 \mu \mathrm{L}, 2 \mathrm{mg} \mathrm{mL}^{-1}$ in $\mathrm{D}_{2} \mathrm{O}$ ) was used as an internal standard for chemical shift measurements. Successive volumes of dendrimers stock solutions in $\mathrm{D}_{2} \mathrm{O}$ at $\mathrm{pD} 1.4$ were added to the NMR tube to obtain different guests: dendrimer molar ratios $(\mathrm{G} / \mathrm{H})$ during the titration. All ${ }^{1} \mathrm{H}$ NMR spectra were recorded under the same experimental conditions of the previous work. ${ }^{14}$

The chemical shift variations $\left(\Delta \delta_{\text {obs }}\right)$ of guest protons as a function of the $\mathrm{G} / \mathrm{H}$ ratio can be expressed through eq $2^{9}$

$$
\begin{aligned}
\Delta \delta_{\mathrm{obs}}= & \frac{\Delta \delta_{\max }}{2}\left\{\left(1+\frac{1}{K[\text { Guest }]}+\frac{n[\text { Dend }]}{[\text { Guest }]}\right)\right. \\
& \left.-\left[\left(1+\frac{1}{K[\text { Guest }]}+\frac{n[\text { Dend }]}{[\text { Guest }]}\right)^{2}-\frac{4 n[\text { Dend }]}{[\text { Guest }]}\right]^{1 / 2}\right\}
\end{aligned}
$$

$\Delta \delta_{\max }$ is the maximum chemical shift variation of the guest molecule in the NMR titration experiment and $K$ is the binding affinity or association constant. The number of binding sites $(n)$ was obtained by fitting the titration data with eq 2 using a nonlinear least-squares method within the software program Microsoft Excel.

UV-vis Spectroscopy. $p K_{a}$ Determination. MePyCy3glc stock solution at $191 \mu \mathrm{M}$ and dendrimer stock solution at $84.3 \mu \mathrm{M}$ were prepared in water with $0.1 \mathrm{M} \mathrm{HCl}$. In a plastic cell with $1 \mathrm{~cm}$ of optical path, $300 \mu \mathrm{L}$ of the Theorell and Stenhagen universal buffer at $\mathrm{pH} 1,300 \mu \mathrm{L}$ of a $0.1 \mathrm{M} \mathrm{NaOH}$ solution, $150 \mu \mathrm{L}$ of the dendrimer stock solution, and $150 \mu \mathrm{L}$ of the dye stock solution (the dye and dendrimer final concentration were 32 and $14 \mu \mathrm{M}$, respectively) were added. In the case of the titration in the absence of the dendrimer, $150 \mu \mathrm{L}$ of $0.1 \mathrm{M} \mathrm{HCl}$ solution was used. The titrations were performed until $\mathrm{pH} 12$ by the addition of small volumes of $\mathrm{NaOH} 1$ $\mathrm{M}$ solution. Successive spectra were recorded immediately after the addition of the base in a Thermo Scientific Evolution Array UV-vis spectrophotometer at $25{ }^{\circ} \mathrm{C}$. The titrations were performed in triplicate. Final volumes were appropriately corrected. All $\mathrm{pH}$ measurements were made in a Radiometer Copenhagen PHM240 $\mathrm{pH} /$ ion meter. The fitting for $\mathrm{p} K_{\mathrm{a}}$ determination was carried out using Solver program from Microsoft Excel.

The protonation/deprotonation reactions can be accounted to the global process through eqs 3-5

$$
\begin{aligned}
& \mathrm{AH}^{+}+\mathrm{H}_{2} \mathrm{O} \leftrightarrow \mathrm{A}+\mathrm{H}_{3} \mathrm{O}^{+} \quad K_{\mathrm{a} 1} \\
& \mathrm{~A}+\mathrm{H}_{2} \mathrm{O} \leftrightarrow \mathrm{A}^{-}+\mathrm{H}_{3} \mathrm{O}^{+} \quad K_{\mathrm{a} 2} \\
& \mathrm{~A}^{-}+\mathrm{H}_{2} \mathrm{O} \leftrightarrow \mathrm{A}^{(2-)}+\mathrm{H}_{3} \mathrm{O}^{+} \quad K_{\mathrm{a} 3}
\end{aligned}
$$

where

$$
K_{\mathrm{a} 1}=\frac{[\mathrm{A}] \cdot\left[\mathrm{H}_{3} \mathrm{O}^{+}\right]}{\left[\mathrm{AH}^{+}\right]} \quad K_{\mathrm{a} 2}=\frac{\left[\mathrm{A}^{-}\right] \cdot\left[\mathrm{H}_{3} \mathrm{O}^{+}\right]}{[\mathrm{A}]} \quad K_{\mathrm{a} 3}=\frac{\left[\mathrm{A}^{2-}\right] \cdot\left[\mathrm{H}_{3} \mathrm{O}^{+}\right]}{\left[\mathrm{A}^{-}\right]}
$$

The total concentration of individual species, $C_{0}$, is given by eq 7

$$
C_{0}=\left[\mathrm{AH}^{+}\right]+[\mathrm{A}]+\left[\mathrm{A}^{-}\right]+\left[\mathrm{A}^{2-}\right]
$$

and the mole fraction distribution of the different species, $\chi_{i}$, was calculated as follows

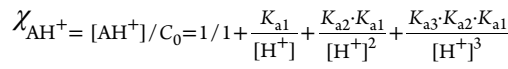

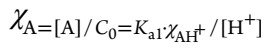

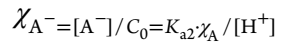

$$
\begin{aligned}
& \chi_{\mathrm{A}^{2-}=\left[\mathrm{A}^{2-}\right] / \mathrm{C}_{0}=K_{\mathrm{a} 3} \cdot \chi_{\mathrm{A}}-/\left[\mathrm{H}^{+}\right]}
\end{aligned}
$$

The $\mathrm{p} K_{\mathrm{a}}$ values were determined by fitting the experimental data (absorbance as a function of $\mathrm{pH}$ ) at a given wavelength using eq 12 .

$$
\text { fitting }=\varepsilon_{\mathrm{AH}^{+}} \cdot \chi_{\mathrm{AH}^{+}}+\varepsilon_{\mathrm{A}} \cdot \chi_{\mathrm{A}}+\varepsilon_{\mathrm{A}^{-}} \cdot \chi_{\mathrm{A}^{-}}+\varepsilon_{\mathrm{A}^{2-} \cdot \chi_{\mathrm{A}^{2-}}}
$$

where $\varepsilon_{\mathrm{AH}^{+}}, \varepsilon_{\mathrm{A}}, \varepsilon_{\mathrm{A}^{-}}$, and $\varepsilon_{\mathrm{A}^{2-}}$ are the mole absorption coefficients of the individual species or components at the considered wavelength.

Apparent Association Constant. The apparent association constant $(n K)$ of the complex $\mathrm{MePyCy} 3 \mathrm{glc}-3[\mathrm{G} 4]-\mathrm{OSO}_{3} \mathrm{Na}$ dendrimer was estimated by $\mathrm{UV}-\mathrm{vis}$ spectroscopy in aqueous solutions at $\mathrm{pH} 1$. A solution of $\mathrm{MePyCy} 3 \mathrm{glc}(47.8 \mu \mathrm{M})$ was prepared in $0.1 \mathrm{M} \mathrm{HCl}$ (solution A). Similarly, a solution containing a mixture of $\mathrm{MePyCy} 3 \mathrm{glc}(47.8 \mu \mathrm{M})$ and $3[\mathrm{G} 4]-\mathrm{OSO}_{3} \mathrm{Na}$ dendrimer at the concentration of $6.32 \mu \mathrm{M}$ was prepared (solution $\mathrm{B}$ ). Then, to solution A, a known volume of solution B was added, allowing us to achieve increasing concentrations of dendrimer (from 0.06 to 1.26 $\mu \mathrm{M})$. UV-vis absorption spectra were recorded in a Thermo Scientific Evolution Array UV-vis spectrophotometer from 360 to $830 \mathrm{~nm}$ in a $1 \mathrm{~cm}$ path length cell. The absorbance values variations (Abs) as a function of dendrimer concentration $\left[L_{0}\right]$ can be expressed by eq 13 , previously developed for similar host-guest interactions ${ }^{22}$ 


$$
\mathrm{Abs}=\mathrm{Abs}_{0}+\Delta \mathrm{Abs} \frac{n K\left[L_{0}\right]}{1+n K\left[L_{0}\right]}
$$

where $n K$ is the apparent binding constant, $n$ is the number of nonspecific binding sites of the host where guest can bind, and $\left[L_{0}\right]$ the total concentration of the dendrimer added. The data could be fitted by eq 13 using the nonlinear least-squares method and the Solver function from Microsoft Excel.

\section{RESULTS AND DISCUSSION}

NMR Titration Reveals Two Interaction Modes. The interaction between the dendrimer host $(\mathrm{H})$ and the MePyCy3glc guest (G) was first studied by NMR spectroscopy. A ${ }^{1} \mathrm{H}$ NMR titration was performed in $\mathrm{D}_{2} \mathrm{O}$ at $\mathrm{pD}$ 1.4. The chemical shift variations $\left(\Delta \delta_{\text {obs }}\right)$ of the guest $(261 \mu \mathrm{M})$ protons were followed with increasing concentrations of the dendrimer (Figure 2A). At very low relative concentrations of

A

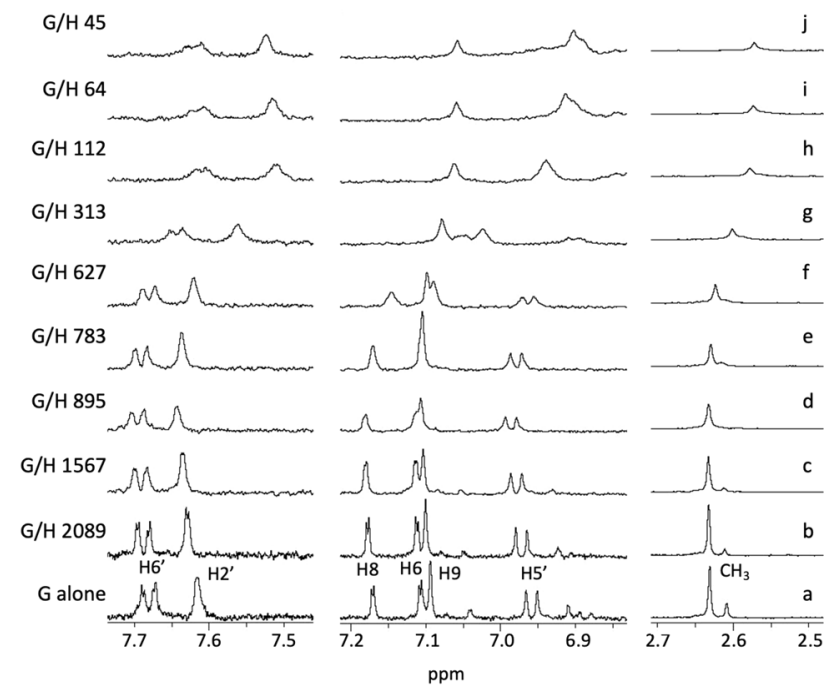

B

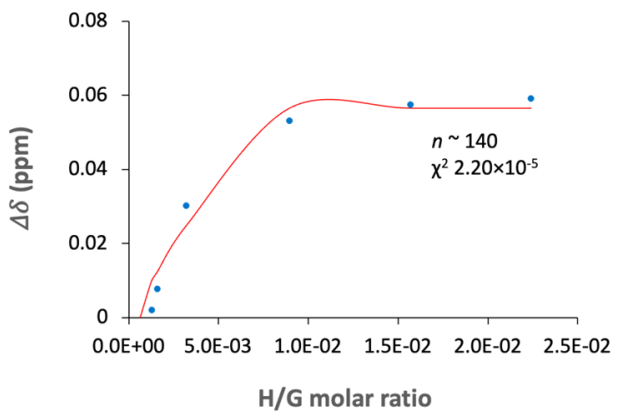

Figure 2. (A) ${ }^{1} \mathrm{H}$ NMR titration of MePyCy3glc $(261 \mu \mathrm{M})$ with increasing concentrations of host dendrimer: (a) no dendrimer; (b) $0.12 \mu \mathrm{M}$; (c) $0.16 \mu \mathrm{M}$; (d) $0.29 \mu \mathrm{M}$; (e) $0.33 \mu \mathrm{M}$; (f) $0.41 \mu \mathrm{M}$; (g) $0.80 \mu \mathrm{M}$; (h) $2.2 \mu \mathrm{M}$; (i) $3.6 \mu \mathrm{M}$; and (j) $5.0 \mu \mathrm{M}$. (B) Chemical shift variation of MePyCy3glc methyl protons as a function of $\mathrm{H} / \mathrm{G}$ molar ratio.

dendrimer (from 0.12 to $0.29 \mu \mathrm{M}, \mathrm{G} / \mathrm{H}$ ratios 2089-895), all aromatic and methyl protons of the guest were shifted downfield (deshielding effect caused by the decrease of the electron density around the hydrogen nucleus ${ }^{23}$ ), suggesting the formation of reversible contact ion pairs between the pyranoflavylium cation and the anionic sulfate groups at the periphery of the dendrimer, an interaction resembling those of anthocyanins $^{14}$ and other host-guest systems with den- drimers. ${ }^{9,24,25}$ At higher dendrimer concentrations (from 0.33 to $2.2 \mu \mathrm{M}, \mathrm{G} / \mathrm{H}$ 783-112), a larger upfield shift of the guest protons was observed (shielding effect caused by the increase of the electron density around the hydrogen nucleus ${ }^{23}$ ), accompanied by a decrease in the intensity of the signals. This trend, not observed with anthocyanins, is compatible with guest molecules penetrating the internal periphery of the dendrimer, ${ }^{9}$ an encapsulation near the anionic surface facilitated by the hydrophobicity of the dye. Interestingly, when control NMR titrations were performed with dendrimers of a similar size and an identical number of peripheral cationic (ammonium) or neutral (hydroxyl) groups, no effect on the chemical shifts of MePyCy3glc were observed (Figures S2 and S3 in the SI), pointing to a selective interaction with the anionic dendrimer.

The number of guest molecules $(n)$ able to bind to the host during the second part of the NMR titration (shielding; $\mathrm{G} / \mathrm{H}$ 783-45) was estimated by fitting the data to eq $29^{9}$ where $\Delta \delta_{\max }$ is the maximum chemical shift variation of the guest molecule and $K$ is the binding affinity. As shown in Figure $2 \mathrm{~B}$ for the methyl protons, a $\Delta \delta_{\max }$ plateau was reached after the addition of ca. $3.6 \mu \mathrm{M}$ of the dendrimer. This afforded a number of binding sites around 140, which represents ca. 1 guest bound to each sulfate group.

UV-vis Spectroscopy Analysis of the Dye Encapsulation. Confirmation of the encapsulation behavior was obtained from UV-vis spectroscopy titration, where the interaction of $\mathrm{MePyCy} 3 \mathrm{glc}$ at a fixed $48 \mu \mathrm{M}$ concentration was studied $\left(\mathrm{H}_{2} \mathrm{O}, \mathrm{pH} 1\right)$ by successive additions of the dendrimer (from 0.06 to $1.26 \mu \mathrm{M}, \mathrm{G} / \mathrm{H} 800-38$ ). A small decrease in the absorbance intensity was revealed along with a bathochromic shift (ca. $7 \mathrm{~nm}$ ) of its maximum wavelength (Figure 3A), effects that are compatible with the cationic guests located at the dendrimer hydrophobic internal periphery
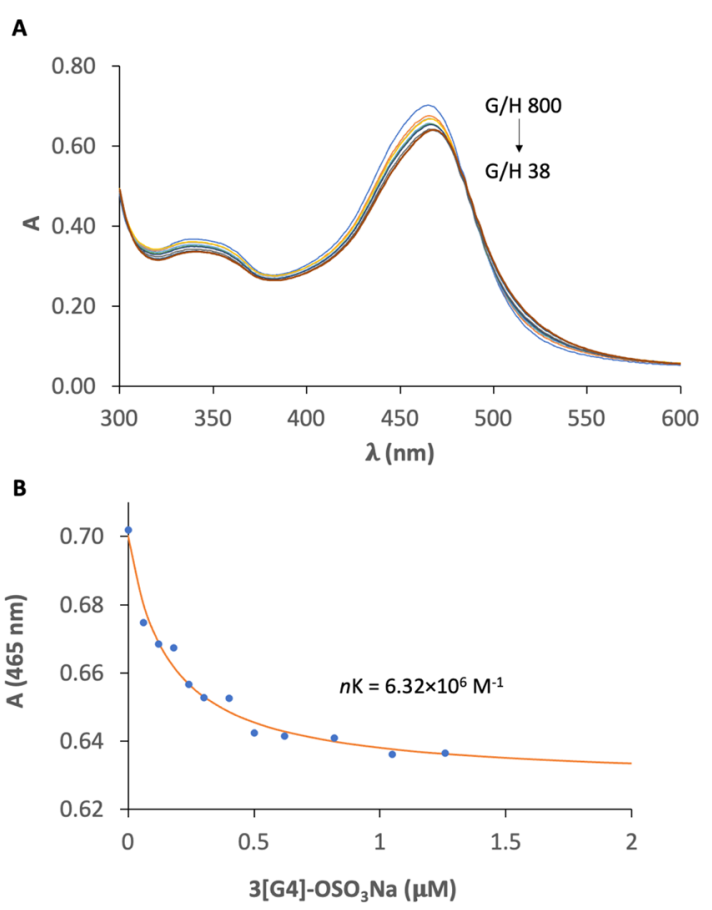

Figure 3. (A) UV-vis titration of MePyCy3glc guest (48 $\mu \mathrm{M})$ with increasing concentrations of $3[\mathrm{G} 4]-\mathrm{OSO}_{3} \mathrm{Na}$ dendrimer (from 0.06 to $1.26 \mu \mathrm{M}$ ) in $\mathrm{H}_{2} \mathrm{O}$ at $\mathrm{pH}$ 1. (B) Fitting the data using eq 13 . 
as observed for other nondendritic, flavylium host-guest systems. $^{26,27}$ From Figure 3B, it was possible to fit the data (eq 13) and obtain an apparent binding constant $n K$ of $6.32 \times 10^{6}$ $\mathrm{M}^{-1}$. From this and the number of binding sites determined by NMR, the binding constant $K$ for the encapsulation process has been estimated to be ca. $4.51 \times 10^{4} \mathrm{M}^{-1}$. This value is the in the same order of magnitude as the one obtained for the interaction between cyanidin-3-glucoside and a low methyl esterified fraction of pectic polysaccharides recently reported. ${ }^{28}$

DOSY, NOESY, and $T_{2}$ Relaxation. To understand the host-guest interaction phenomena along the titration, diffusion-ordered NMR spectroscopy (DOSY), nuclear overhauser effects (NOESY), and transverse relaxation $\left(T_{2}\right)$ experiments were performed. Indeed, NMR is a powerful tool to study intermolecular interactions, where the variations of the chemical shifts, diffusion, NOE, and relaxation properties of the guest upon macromolecular binding can be exploited as a measure of the process. ${ }^{29}$

Since the molecular weight of the host dendrimer is ca. 100 times higher than that of the guest, their diffusion coefficients (D) constitute a useful tool to assess the interaction. As expected, the dendrimer alone revealed a slower $D=0.56 \times$ $10^{-10} \mathrm{~m}^{2} \mathrm{~s}^{-1}(8 \mu \mathrm{M})$ than the dye $D=5.1 \times 10^{-10} \mathrm{~m}^{2} \mathrm{~s}^{-1}(261$ $\mu \mathrm{M})$. In the case of a supramolecular host-guest interaction, both species in the complex should diffuse at the slower rate of the host, effectively reducing the diffusion of the guest. The diffusion coefficient of MePyCy3glc $(261 \mu \mathrm{M})$ was measured after successive additions of the dendrimer ( $\mathrm{G} / \mathrm{H}$ 2089-45). As shown in Figure 4A, the diffusion coefficient of the guest
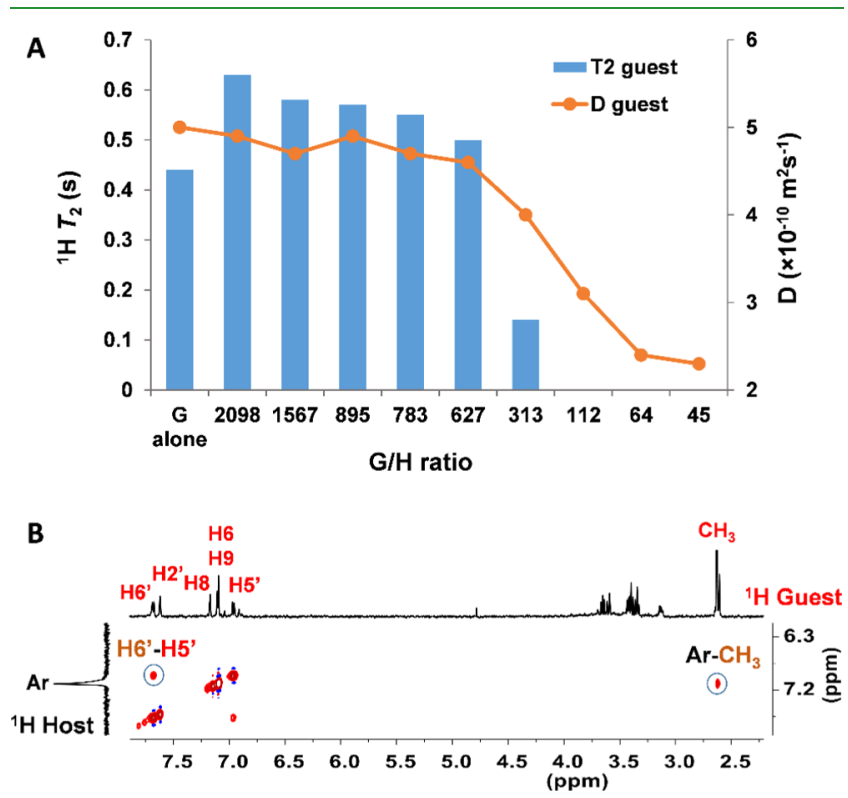

Figure 4. (A) Diffusion coefficients $(D)$ and transverse relaxation times $\left({ }^{1} \mathrm{H} \mathrm{T}_{2}\right.$ ) of MePyCy3glc (methyl protons, $261 \mu \mathrm{M}$ ) obtained after successive additions of dendrimer ( $\mathrm{G} / \mathrm{H}$ 2089-45). (B) NOESY spectrum showing a correlation between protons of the guest and the dendrimer ( $\mathrm{G} / \mathrm{H} 627)$.

did not change during the first part of the titration (which coincided with the deshielding effect) and started to decrease continuously only after a $\mathrm{G} / \mathrm{H}$ ratio of 783 was reached (marking the deshielding-shielding transition). In the first part of the titration, the dendrimer is saturated and there is still a substantial amount of pyranoflavylium cation in the aqueous phase. Below G/H values of about 313, most of the pyranoflavylium cation is bound onto the dendrimer.

To gain a deeper insight into the guest encapsulation, NOESY spectra were recorded $(261 \mu \mathrm{M}$ guest) with the increasing concentrations of dendrimer (from 0.1 to $5 \mu \mathrm{M}$ ). Again, only after the addition of $0.33 \mu \mathrm{M}$ dendrimer $(\mathrm{G} / \mathrm{H}$ 783 ), it was possible to see a strong correlation between the guest and dendrimer protons, namely, an intense cross-peak between the methyl of the guest and the aromatic protons of the gallic acid repeating unit $(7.10 \mathrm{ppm})$ at the dendrimer scaffold (Figure 4B).

Having confirmed the encapsulation of the MePyCy3glc into the dendrimer periphery at $\mathrm{G} / \mathrm{H}$ ratios below 783 through DOSY and NOESY experiments, we performed a series of relaxation experiments to shed light on the early phases of the titration, where the guest is in large excess with respect to the host. Certainly, the reduction of transverse relaxation times $\left(T_{2}\right)$ of low-molecular-weight ligands binding to macromolecular receptors is often analyzed in recognition studies. ${ }^{30-32}$ The ${ }^{1} \mathrm{H} T_{2}$ of the guest was analyzed by increasing the dendrimer concentration. As seen in Figure 4A for the methyl protons, the ${ }^{1} \mathrm{H} T_{2}$ values increase after the first addition of dendrimer $(\mathrm{G} / \mathrm{H} 2089)$ to level off afterward during the first part of the titration and suddenly decrease once the $\mathrm{G} / \mathrm{H}$ ratios at the deshielding-shielding transition are reached (see Table S1 and Figure S1 in the SI for a whole set of ${ }^{1} \mathrm{H} T_{2}$ data and representative magnetization decays). The initial increase and leveling of $T_{2}$ values are counterintuitive. One would expect a continuous decrease of $T_{2}$ associated with the reduced dynamics and overall tumbling of the guest upon binding the macromolecular host. The observed initial increase reveals an opposite behavior, which is interpreted as resulting from the deaggregation process of the dye in the presence of the dendrimer. The enhanced hydrophobic character of MePyCy3glc compared to structurally simpler anthocyanins results in a higher tendency to self-assemble in $\mathrm{H}_{2} \mathrm{O}$ as confirmed by dynamic light scattering analysis of a solution of the dye at the same concentration as in the NMR experiments (Figure S4). This results in lower ${ }^{1} \mathrm{H} T_{2}$ values than that expected according to its molecular weight. As depicted in Figure 5, the addition of the anionic dendrimer triggers the deaggregation of the guest by electrostatic interactions at the dendrimer periphery as revealed by the higher ${ }^{1} \mathrm{H} T_{2}$ values observed (characteristic of deaggregated dye) and signal deshielding (ion-paired dye). While only a small fraction of the freely solvated pyranoanthocyanin might actually internalize the host threedimensional structure at the initial $\mathrm{G} / \mathrm{H}$ ratios of the titration (not enough dendrimer available), as the dendrimer concentration increases, a larger fraction of dye will be encapsulated (lower $T_{2}$ and $D$, NOESY, resonance shielding). Overall, the $T_{2}$ and $D$ values determined at any $\mathrm{G} / \mathrm{H}$ ratio combine the contributions of aggregated, deaggregated, ionpaired, and encapsulated MePyCy3glc. This explains the observed variations of chemical shifts, $T_{2}$ and $D$ during the first part of the titration (Figure 5). Beyond the deshieldingshielding transition, the dendrimer concentration is so high that the encapsulation (short $T_{2}$ and $D$ ) becomes dominant as also evidenced by the decreased intensity of the guest signals. Indeed, the inverse proportionality between ${ }^{1} \mathrm{H} T_{2}$ and the spectral linewidth ${ }^{33}$ explains the broadening of the pyranoanthocyanin resonances as the titration progresses (Figure 2A).

$\mathrm{p} K_{\mathrm{a}}$ Determination. With the aim of determining the effect of the encapsulation on the thermodynamic constants of 


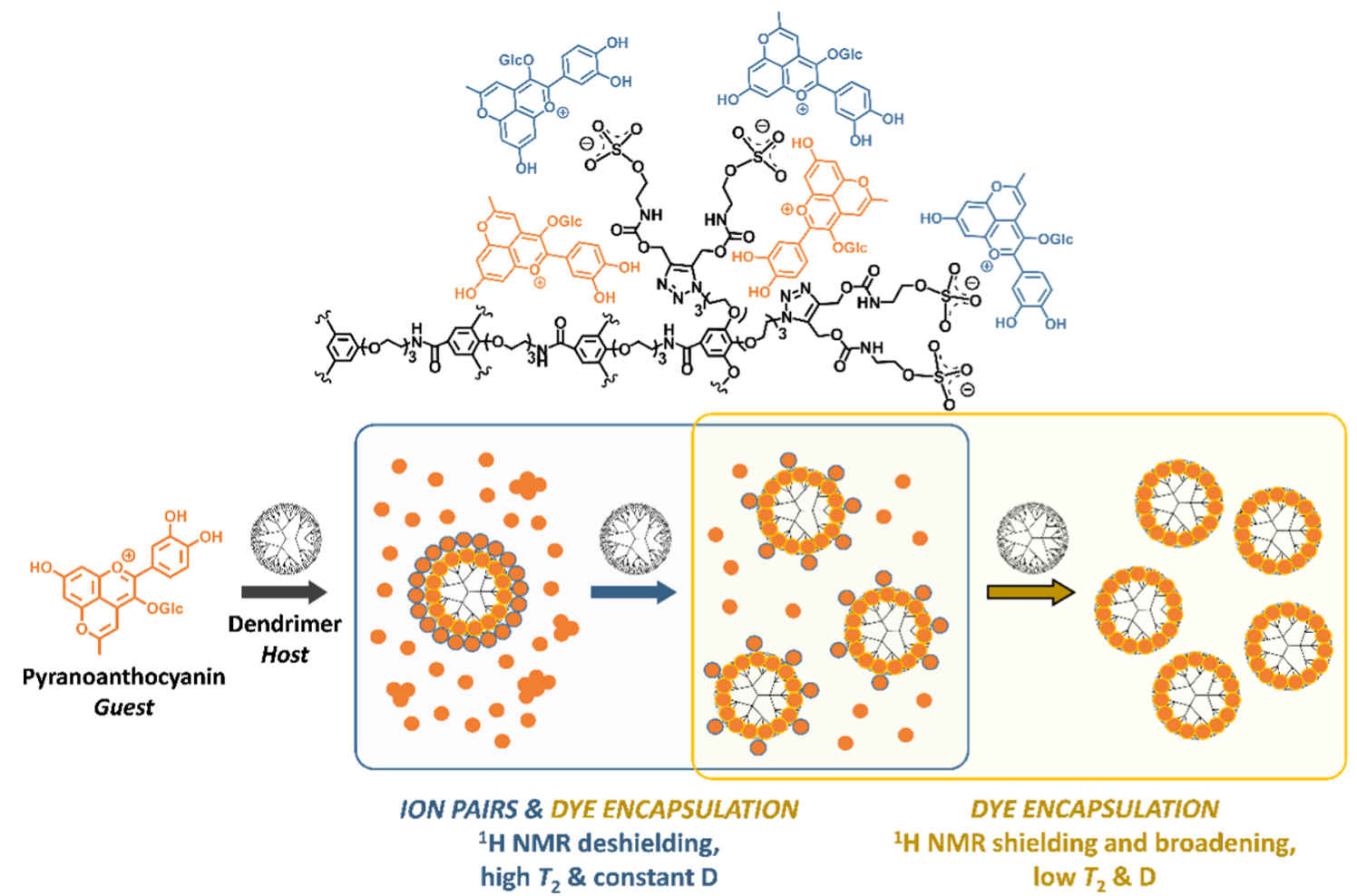

Figure 5. Host-guest interaction modes along the titration. At high $\mathrm{G} / \mathrm{H}$ ratios, ion-paired MePyCy3glc at the dendrimer periphery prevail over dye encapsulation (and coexist with aggregated and deaggregated dye in excess). On increasing the dendrimer concentration, dye encapsulation becomes the dominant interaction.

MePyCy3glc, a UV-vis titration of a dendrimer $(14 \mu \mathrm{M})$ and MePyCy3glc $(32 \mu \mathrm{M})$ solution (G/H 2.3) was recorded between $\mathrm{pH} 1.5$ and 12 (Figure 6A). After the fitting, two deprotonation constants were obtained: $\mathrm{p} K_{\mathrm{a} 1}=6.1 \pm 0.1$ and $\mathrm{p} K_{\mathrm{a} 2}=10.7 \pm 0.1$ (Figure $6 \mathrm{~B}$ ). In the absence of the dendrimer, the thermodynamic constants of the pigment were $\mathrm{p} K_{\mathrm{a} 1}=5.6 \pm 0.1$ and $\mathrm{p} K_{\mathrm{a} 2}=10.4 \pm 0.1$. The results indicate a color enhancement of the pigment in the presence of the dendrimer toward higher $\mathrm{pH}$ values and preferential stabilization of the pyranoflavylium cation species $\left(\mathrm{AH}^{+}\right)$ rather than the neutral quinoidal base (A), increasing its first acidic constant in $0.5 \mathrm{pH}$ units. The data obtained is in agreement with alternate more traditional systems, namely, anionic SDS micelles, used to tune the thermodynamic constants of similar pigments. ${ }^{34}$

\section{CONCLUSIONS}

Dendrimers have recently emerged as hosts of hydrophilic anthocyanin guests to stabilize their red color. In this study, a global mechanistic perspective about the interaction with a promising, more hydrophobic pyranoanthocyanin dye (MePyCy3glc) is given, which illustrates how the structure and concentration of the dye modulate the interactions involved. NMR and UV-vis titration experiments demonstrate that at low dendrimer-to-dye concentrations, the formation of expected ion pairs at the dendrimer periphery coexists with the molecular inclusion of $\mathrm{MePyCy} 3 \mathrm{glc}$ into the threedimensional dendritic structure. This encapsulation, previously unseen with structurally simpler anthocyanins and promoted by the more hydrophobic nature of this dye, becomes dominant as the dendrimer-to-dye concentration increases. These results provide new insights into the ability of GATGbased dendrimers to host structurally diverse pyranoflavylium-

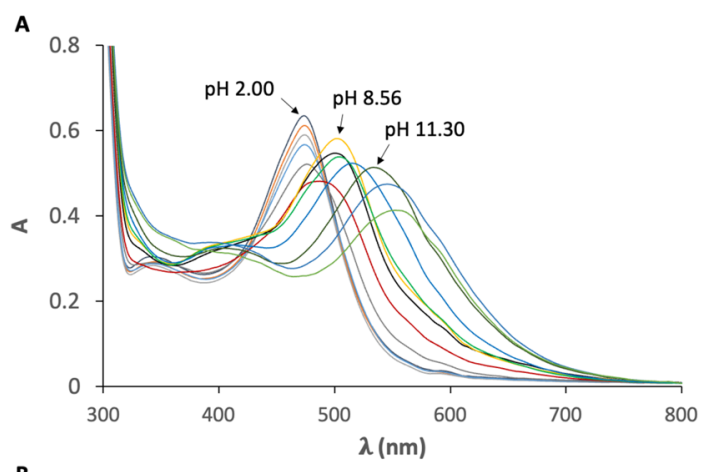

B

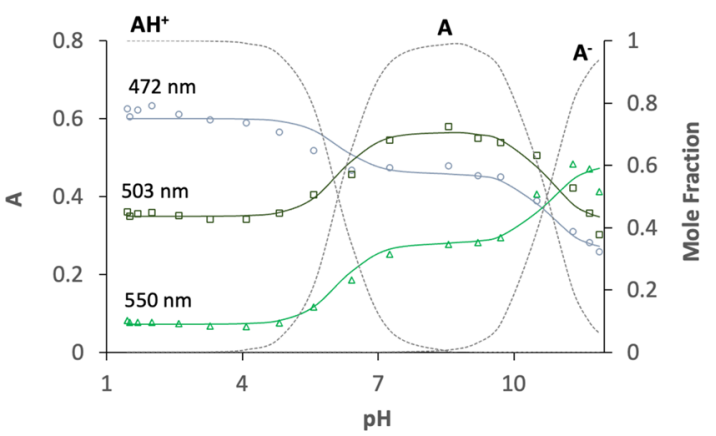

Figure 6. (A) UV-vis spectral variations of $\mathrm{MePyCy} 3 g l c(32 \mu \mathrm{M})$ as a function of $\mathrm{pH}$ in the presence of dendrimer $(14 \mu \mathrm{M})$ ( $\mathrm{pH}$ range 2.00-11.30). (B) Fitting of the experimental data using eq 12 at a given wavelength and respective mole fraction distribution as a function of $\mathrm{pH}: \mathrm{pK}_{\mathrm{a} 1}=6.1 \pm 0.1$ and $\mathrm{p} K_{\mathrm{a} 2}=10.7 \pm 0.1$.

type dyes with applications as new smart systems for real-time monitoring of $\mathrm{pH}$ changes of perishable foods and, therefore, 
to detect spoilage at early stages rather than conventional preestimated expiry dates.

\section{ASSOCIATED CONTENT}

\section{SI Supporting Information}

The Supporting Information is available free of charge at https://pubs.acs.org/doi/10.1021/acsapm.0c01321.

Relaxation times of MePyCy3glc with the addition of dendrimer (Table S1); magnetization decay in CPMG experiments of MePyCy3glc with the addition of dendrimer (Figure S1); titrations of MePyCy3glc with control cationic $3[\mathrm{G} 4]-\mathrm{NH}_{2} \cdot \mathrm{HCl}$ host dendrimer and control neutral 3[G4]-OH dendrimer (Figures S2 and S3); ${ }^{1} \mathrm{H}$ NMR, ${ }^{1} \mathrm{H}-{ }^{1} \mathrm{H} 2 \mathrm{D}$ COSY, ${ }^{1} \mathrm{H}-{ }^{13} \mathrm{C} 2 \mathrm{D}$ HSQC, and ${ }^{1} \mathrm{H}-{ }^{13} \mathrm{C}$ 2D HMBC spectra of MePyCy3glc (Figures S4-S7); and ${ }^{1} \mathrm{H}$ and ${ }^{13} \mathrm{C}$ NMR spectra of $3[\mathrm{G} 4]-\mathrm{OSO}_{3} \mathrm{Na}, 3[\mathrm{G} 4]-\mathrm{NH}_{2} \cdot \mathrm{HCl}$, and $3[\mathrm{G} 4]-\mathrm{OH}$ (Figures S8-S13) (PDF)

\section{AUTHOR INFORMATION}

\section{Corresponding Authors}

Luís Cruz - REQUIMTE/LAQV, Departamento de Química e Bioquímica, Faculdade de Ciências, Universidade do Porto, 4169-007 Porto, Portugal; ○ orcid.org/0000-0003-22260404; Email: luis.cruz@fc.up.pt

Eduardo Fernandez-Megia - Centro Singular de Investigación en Química Biolóxica e Materiais Moleculares (CIQUS) and Departamento de Química Orgánica, Universidade de Santiago de Compostela, 15782 Santiago de Compostela, Spain; (1) orcid.org/0000-0002-0405-4933; Email: ef.megia@usc.es

\section{Authors}

Juan Correa - Centro Singular de Investigación en Química Biolóxica e Materiais Moleculares (CIQUS) and Departamento de Química Orgánica, Universidade de Santiago de Compostela, 15782 Santiago de Compostela, Spain

Nuno Mateus - REQUIMTE/LAQV, Departamento de Química e Bioquímica, Faculdade de Cîncias, Universidade do Porto, 4169-007 Porto, Portugal

Victor de Freitas - REQUIMTE/LAQV, Departamento de Química e Bioquímica, Faculdade de Cîncias, Universidade do Porto, 4169-007 Porto, Portugal; (i) orcid.org/00000003-0586-2278

Maun H. Tawara - Centro Singular de Investigación en Química Biolóxica e Materiais Moleculares (CIQUS) and Departamento de Química Orgánica, Universidade de Santiago de Compostela, 15782 Santiago de Compostela, Spain

Complete contact information is available at:

https://pubs.acs.org/10.1021/acsapm.0c01321

\section{Notes}

The authors declare no competing financial interest.

\section{ACKNOWLEDGMENTS}

The authors thank Dr. Mariana Andrade for the NMR analysis. This research was supported by a research project grant (PTDC/OCE-ETA/31250/2017) with financial support from FCT/MCTES through national funds and co-financed by FEDER, under the Partnership Agreement PT2020 (UID/
QUI/50006/2020, POCI/01/0145/FEDER/007265). This research was conducted under the project AgriFood XXINORTE-01-0145-FEDER-000041, financed by European Regional Development Fund (FEDER) through North Portugal Regional Operational Programme (Norte 2020). Financial support was also obtained from the Spanish Ministry of Science and Innovation (RTI2018-102212-B-I00), Xunta de Galicia (ED431C 2018/30 and Centro singular de investigación de Galicia accreditation 2019-2022, ED431G 2019/ 03), Axencia Galega de Innovación (IN845D 2020/09), and the European Union (European Regional Development FundERDF). L.C. gratefully acknowledges the research FCT contract.

\section{REFERENCES}

(1) Pina, F.; Melo, M. J.; Laia, C. A. T.; Parola, A. J.; Lima, J. C. Chemistry and applications of flavylium compounds: a handful of colours. Chem. Soc. Rev. 2012, 41, 869-908.

(2) De Freitas, V.; Mateus, N. Formation of pyranoanthocyanins in red wines: a new and diverse class of anthocyanin derivatives. Anal. Bioanal. Chem. 2011, 401, 1463-1473.

(3) Cruz, L.; Petrov, V.; Teixeira, N.; Mateus, N.; Pina, F.; De Freitas, V. Establishment of the Chemical Equilibria of Different Types of Pyranoanthocyanins in Aqueous Solutions: Evidence for the Formation of Aggregation in Pyranomalvidin-3-O-coumaroylglucoside-(+)-catechin. J. Phys. Chem. B 2010, 114, 13232-13240.

(4) Sousa, J. L. C.; Gomes, V.; Mateus, N.; Pina, F.; de Freitas, V.; Cruz, L. Synthesis and equilibrium multistate of new pyrano-3deoxyanthocyanin-type pigments in aqueous solutions. Tetrahedron 2017, 73, 6021-6030.

(5) Oliveira, J.; Mateus, N.; De Freitas, V. Previous and recent advances in pyranoanthocyanins equilibria in aqueous solution. Dyes Pigm. 2014, 100, 190-200.

(6) Ma, X.; Zhao, Y. Biomedical Applications of Supramolecular Systems Based on Host-Guest Interactions. Chem. Rev. 2015, 115, 7794-7839.

(7) Sinawang, G.; Osaki, M.; Takashima, Y.; Yamaguchi, H.; Harada, A. Supramolecular self-healing materials from non-covalent crosslinking host-guest interactions. Chem. Commun. 2020, 56, 43814395.

(8) Trouillas, P.; Sancho-García, J. C.; De Freitas, V.; Gierschner, J.; Otyepka, M.; Dangles, O. Stabilizing and Modulating Color by Copigmentation: Insights from Theory and Experiment. Chem. Rev. 2016, 116, 4937-4982.

(9) $\mathrm{Hu}$, J.; Xu, T.; Cheng, Y. NMR Insights into Dendrimer-Based Host-Guest Systems. Chem. Rev. 2012, 112, 3856-3891.

(10) Astruc, D.; Boisselier, E.; Ornelas, C. Dendrimers Designed for Functions: From Physical, Photophysical, and Supramolecular Properties to Applications in Sensing, Catalysis, Molecular Electronics, Photonics, and Nanomedicine. Chem. Rev. 2010, 110, 18571959.

(11) Caminade, A.-M.; Turrin, C.-O.; Laurent, R.; Ouali, A.; Delavaux-Nicot, B. Dendrimers: Towards Catalytic, Material and Biomedical Uses; John Wiley \& Sons, Ltd: Chichester, U.K., 2011.

(12) Amaral, S. P.; Tawara, M. H.; Fernandez-Villamarin, M.; Borrajo, E.; Martínez-Costas, J.; Vidal, A.; Riguera, R.; FernandezMegia, E. Tuning the Size of Nanoassembles: A Hierarchical Transfer of Information from Dendrimers to Polyion Complexes. Angew. Chem., Int. Ed. 2018, 57, 5273-5277.

(13) Fernandez-Megia, E.; Correa, J.; Rodríguez-Meizoso, I.; Riguera, R. A Click Approach to Unprotected Glycodendrimers. Macromolecules 2006, 39, 2113-2120.

(14) Cruz, L.; Basílio, N.; Mendoza, J.; Mateus, N.; de Freitas, V.; Tawara, M. H.; Correa, J.; Fernandez-Megia, E. Impact of a WaterSoluble Gallic Acid-Based Dendrimer on the Color-Stabilizing Mechanisms of Anthocyanins. Chem. - Eur. J. 2019, 25, 11696-11706. 
(15) Küster, W. F.; Thiel, A. Tabelle per le analisi chimiche e chimicofisiche, 12th ed.; Hoepli: Milano, 1982.

(16) Guimarães, M.; Mateus, N.; de Freitas, V.; Cruz, L. Improvement of the Color Stability of Cyanidin-3-glucoside by Fatty Acid Enzymatic Acylation. J. Agric. Food Chem. 2018, 66, 10003-10010.

(17) Gomes, V.; Mateus, N.; de Freitas, V.; Cruz, L. Synthesis and Structural Characterization of a Novel Symmetrical 2,10-Bis-Styryl-1Benzopyrylium Dye. Synlett 2018, 29, 1390-1394.

(18) Wu, D. H.; Chen, A. D.; Johnson, C. S. An Improved DiffusionOrdered Spectroscopy Experiment Incorporating Bipolar-Gradient Pulses. J. Magn. Reson., Ser. A 1995, 115, 260-264.

(19) Fernandes, A.; Ivanova, G.; Bras, N. F.; Mateus, N.; Ramos, M. J.; Rangel, M.; de Freitas, V. Structural characterization of inclusion complexes between cyanidin-3-0-glucoside and beta-cyclodextrin. Carbohydr. Polym. 2014, 102, 269-277.

(20) Carr, H. Y.; Purcell, E. M. Effects of Diffusion on Free Precession in Nuclear Magnetic Resonance Experiments. Phys. Rev. 1954, 94, 630-638.

(21) Meiboom, S.; Gill, D. Modified Spin-Echo Method for Measuring Nuclear Relaxation Times. Rev. Sci. Instrum. 1958, 29, $688-691$.

(22) Araújo, P.; Basílio, N.; Fernandes, A.; Mateus, N.; de Freitas, V.; Pina, F.; Oliveira, J. Impact of Lignosulfonates on the Thermodynamic and Kinetic Parameters of Malvidin-3-O-glucoside in Aqueous Solutions. J. Agric. Food Chem. 2018, 66, 6382-6387.

(23) Slichter, C. P. Principles of Magnetic Resonance; Springer: New York, 2010.

(24) Boisselier, E.; Ornelas, C.; Pianet, I.; Aranzaes, J. R.; Astruc, D. Four Generations of Water-Soluble Dendrimers with 9 to 243 Benzoate Tethers: Synthesis and Dendritic Effects on Their Ion Pairing with Acetylcholine, Benzyltriethylammonium, and Dopamine in Water. Chem. - Eur. J. 2008, 14, 5577-5587.

(25) Ornelas, C.; Boisselier, E.; Martinez, V.; Pianet, I.; Ruiz Aranzaes, J.; Astruc, D. New water-soluble polyanionic dendrimers and binding to acetylcholine in water by means of contact ion-pairing interactions. Chem. Commun. 2007, 5093-5095.

(26) Basílio, N.; Pina, F. Flavylium Network of Chemical Reactions in Confined Media: Modulation of $3^{\prime}, 4^{\prime}, 7$-Trihydroxyflavilium Reactions by Host-Guest Interactions with Cucurbit[7]uril. ChemPhysChem 2014, 15, 2295-2302.

(27) Lima, J. C.; Vautier-Giongo, C.; Lopes, A.; Melo, E.; Quina, F. H.; Macanita, A. L. Color stabilization of anthocyanins: Effect of SDS micelles on the acid-base and hydration kinetics of malvidin 3glucoside (Oenin). J. Phys. Chem. A 2002, 106, 5851-5859.

(28) Fernandes, A.; Oliveira, J.; Fonseca, F.; Ferreira-da-Silva, F.; Mateus, N.; Vincken, J.-P.; de Freitas, V. Molecular binding between anthocyanins and pectic polysaccharides - Unveiling the role of pectic polysaccharides structure. Food Hydrocolloids 2020, 102, No. 105625.

(29) Pellecchia, M.; Bertini, I.; Cowburn, D.; Dalvit, C.; Giralt, E.; Jahnke, W.; James, T. L.; Homans, S. W.; Kessler, H.; Luchinat, C.; Meyer, B.; Oschkinat, H.; Peng, J.; Schwalbe, H.; Siegal, G. Perspectives on NMR in drug discovery: a technique comes of age. Nat. Rev. Drug Discovery 2008, 7, 738-745.

(30) Verdier, L.; Gharbi-Benarous, J.; Bertho, G.; Evrard-Todeschi, N.; Mauvais, P.; Girault, J.-P. Dissociation-equilibrium constant and bound conformation for weak antibiotic binding interaction with different bacterial ribosomes. J. Chem. Soc., Perkin Trans. 2 2000, 2363-2371.

(31) Dubois, B. W.; Evers, A. S. 19F-NMR spin-spin relaxation (T2) method for characterizing volatile anesthetic binding to proteins. Analysis of isoflurane binding to serum albumin. Biochemistry 1992, 31, 7069-7076.

(32) Fischer, J. J.; Jardetzky, O. Nuclear Magnetic Relaxation Study of Intermolecular Complexes. The Mechanism of Penicillin Binding to Serum Albumin. J. Am. Chem. Soc. 1965, 87, 3237-3244.
(33) La Mar, G. N.; de Ropp, J. S. Biological Magnetic Resonance; Berliner, L. J.; Reuben, J., Eds.; Plenum Press: New York, 1993; Vol. 12, $\mathrm{p} 1$.

(34) Gomes, V.; Mateus, N.; de Freitas, V.; Cruz, L. Synthesis and chemical equilibria of a new 10-methylpyrano-2-styrylbenzopyrylium pigment in aqueous solution and its modulation by different micellar systems. Dyes Pigm. 2019, 167, 60-67. 